\title{
EMPLOYMENT AND SELF-EMPLOYMENT IN THE WAKE OF HURRICANE KATRINA*
}

\author{
JULIE ZISSIMOPOULOS AND LYNN A. KAROLY
}

\begin{abstract}
We use data from the monthly Current Population Survey to examine the short- and longer-term effects of Hurricane Katrina on the labor market outcomes of prime-age individuals in the most affected states-Alabama, Florida, Louisiana, and Mississippi-and for evacuees in any state. We focus on rates of labor force participation, employment, and unemployment, and we extend prior research by also examining rates of self-employment. With the exception of Mississippi, employment and unemployment one year after the hurricane were at similar rates as the end of 2003. This aggregate pattern of labor market shock and recovery has been observed for other disasters but masks important differences among subgroups. Those evacuated from their residences, even temporarily, were a harder-hit group, and evacuees who had yet to return to their pre-Katrina state up to one year later were hit especially hard; these findings hold even after controlling for differences in observable characteristics. We also find evidence of an important role for self-employment as part of post-disaster labor market recovery, especially for evacuees who did not return. This may result from poor job prospects in the wage and salary sector or new opportunities for starting businesses in the wake of Katrina.
\end{abstract}

ear 2005 brought four severe hurricanes to the U.S. Gulf states, including Hurricane Katrina, an exceptional storm in terms of its magnitude of destruction. Table 1 provides an overview of the 2005 hurricane season, listing the named hurricanes that made landfall in the United States, the states affected, the month of first landfall, and the dollar damages as reported by the U.S. Department of Commerce (2006) and Pielke et al. (2008). Katrina, which reached Category 3 strength at landfall, was by far the most destructive storm that year, with estimated damages of nearly $\$ 100$ billion dollars and primarily affecting the states of Alabama, Florida, Louisiana, and Mississippi (the latter three being states where Katrina made landfall). ${ }^{1}$ Hurricanes Cindy and Dennis in July preceded Katrina. Katrina was then followed by two other Category 3 storms: Rita in September and Wilma in October. Prior to Katrina, Hurricane Andrew in 2002 had been the most costly in nominal dollars with estimated damages of approximately $\$ 27$ billion (Pielke et al. 2008).

Estimates of total dollar damages, however, are just one gauge of the economic consequences of a hurricane. Another important domain of economic impact is the effect of a hurricane or other natural disaster on labor market outcomes. Natural disasters usually involve temporary disruptions to the local economy through direct and indirect effects on local infrastructure; business structures and other business capital; and residences and the population, especially the workforce. In the aftermath of Hurricane Katrina, attention was focused in part on the plight of business owners. Indeed, the cost to business owners of the destruction of capital can be substantial, and the policies intended to aid business

*Julie Zissimopoulos and Lynn A. Karoly, RAND Corporation. Direct correspondence to Julie Zissimopoulos, RAND Corporation, P.O. Box 2138, 1776 Main Street, Santa Monica, CA 90407; e-mail: Julie_Zissimopoulos@ rand.org. This paper results from the RAND Corporation's continuing program of self-initiated research. Support for such research is provided, in part, by the generosity of RAND's donors and by the fees earned on client-funded research. The authors are grateful for the excellent research and programming assistance provided by Qian Gu and Elizabeth Roth, respectively.

1. Estimated damages, as reported by the U.S. Department of Commerce (2006), are based on insurance industry estimates and do not include uninsured losses. Thus, the Department of Commerce uses a factor of two times insured losses to arrive at the estimate. The estimates do not include losses insured by flood insurance coverage (FEMA). Other estimates adjusted for inflation, wealth and population provided by Pielke et al. (2008) are also shown in Table 1. 
Table 1. Named Hurricanes in 2005 Making Landfall in the United States

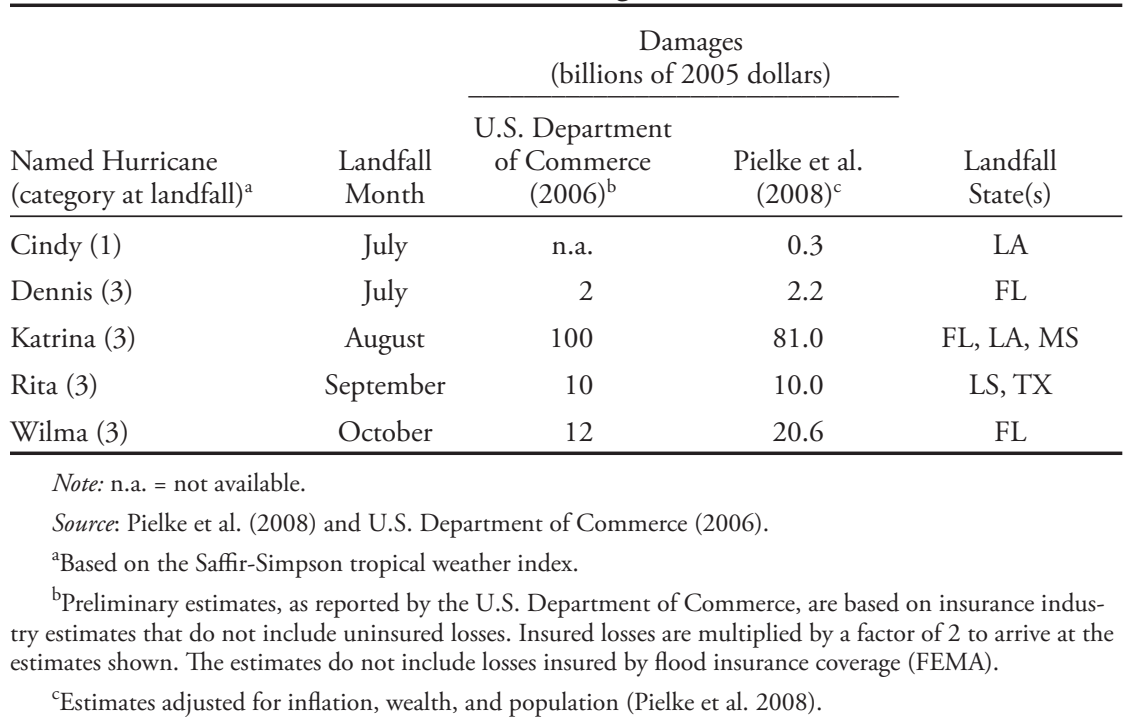

owners may accelerate the pace of economic recovery (see, e.g., Dixon, Macdonald, and Zissimopoulos 2007).

In the case of the 2005 hurricane season, the abnormal number of storms within the span of a few months, as well as the magnitude and geographic scope of the damages, resulted in a particularly large effect on the potential labor force, with an estimated 1.1 million persons age 16 and older evacuating their homes as a result of Katrina alone (Kosanovich 2006). For the populations affected, the storms led to short- and long-distance migration for what became, in some cases, extended periods of time, with the concomitant need to find housing and employment in a new location. Decision makers charged with guiding economic recovery and considering how to handle future disasters will need not only information on the effect of Hurricane Katrina on local employment levels in the short and long term but also details about workers and their jobs, including those displaced to other regions not directly affected by the hurricane.

In this context, the goal of this study is to examine the short- and longer-term effects of Hurricane Katrina on the labor market outcomes of prime-age individuals in the states most affected by the hurricane and for specific groups defined by their evacuation status. Unlike much of the prior literature that has examined the employment impacts of natural disasters based on area-level employment data, we rely on individual-level data from the nationally representative, monthly Current Population Survey (CPS), which allows us to examine various labor market outcomes along with individual demographic characteristics. The addition of several questions to the monthly CPS for one year following Katrina further provides an opportunity, not possible for previous natural disasters, to observe labor market outcomes for populations displaced by the storm, including persons in the affected region as well as those who were displaced to other regions of the United States. Like Vigdor (2007) and Groen and Polivka (2008a, 2008b), who also used the CPS, we examine key labor market outcomes including labor force participation rates, employment rates, and unemployment rates. In addition, we go beyond prior research to differentiate between the share of employed workers in self-employment as compared with wage and salary work in order to understand the role of self-employment in providing temporary and/or longer-term employment. 
To set the stage for our study, we begin in the next section by discussing prior research on the effects of natural disasters on labor market outcomes, small businesses, other measures of economic activity, and demographic behavior. We also discuss findings from the emerging literature that has examined the demographic and economic effects of Hurricane Katrina. In the third section, we briefly discuss the features of the CPS data that we analyze, and we describe our analytic approach. Based on these data, we find that in the states most affected by Hurricane Katrina-Alabama, Florida, Louisiana, and Mississippi-employment and unemployment by the end of 2006 were at rates similar to those at the end of 2003 with the exception of Mississippi, which still had lower employment and higher unemployment at the end of 2006 compared with pre-Katrina levels. One of the groups most affected by the hurricane - the evacuees - had labor force participation rates at the same level as non-evacuees and employment levels and unemployment levels near those of non-evacuees one year after the hurricane.

This result, however, masks important differences for subgroups of evacuees. The group of evacuees that did not return to their pre-Katrina state of residence, even controlling for observable differences, had lower employment rates and higher unemployment rates, both immediately following the hurricane and one year later. Evacuees from different Katrina-affected states had different employment experiences as well. The returning evacuees from Louisiana and Mississippi had higher unemployment rates than non-evacuees from their respective states. In addition, self-employment rates were higher for returning evacuees in all states compared with non-evacuees in those states in the four months immediately following the hurricane but were no different one year later. Non-returnees had the highest rates of self-employment from March to October 2006, although because of small sample sizes, the differences between non-returnees and non-evacuees are statistically different only at the $10 \%$ level. Higher self-employment rates among evacuees may be because of poor job prospects in the wage and salary sector or new opportunities for starting businesses following the hurricane and displacement.

\section{PRIOR RESEARCH}

Researchers from diverse disciplinary perspectives have studied the effects of natural and human-made disasters across the globe on a range of demographic, economic, social, and health outcomes (Rodriguez, Quarantelli, and Dynes 2006; Wright and Rossi 1981). To provide context for our study, we focus this review on research regarding the United States where a range of natural phenomenon such as earthquakes, hurricanes, and tornadoes have been the subject of study in terms of their effects on such outcomes as employment and unemployment, business activity, economic growth, migration, and health. Recent largescale disasters in the United States, including Hurricane Katrina and the September 11, 2001, terrorist attacks in New York, have prompted even more in-depth study as well as innovation in data collection to support those analyses.

A substantial body of research has considered the consequences of various disasters in the United States for labor market outcomes, primarily employment and unemployment (see, e.g., Ewing and Kruse 2005; Ewing, Kruse, and Thompson 2003a, 2003b, 2004, 2009; Kroll et al. 1991). Because many disasters are confined to relatively small geographic areas - and hence, are largely a local labor market phenomenon - researchers have tended to rely on local area employment and unemployment measures from the U.S. Bureau of Labor Statistics, effectively aggregated administrative data that do not capture the demographic characteristics of individual participants in the labor market. These studies generally find that the negative effects of earthquakes, hurricanes, and tornadoes on employment or unemployment rates are short lived, with an eventual recovery that can even surpass predisaster outcomes. This general pattern, however, often conceals substantial differences in the post-disaster labor market dynamics that can occur by industry and proximity to the damaged area. For example, the finance, insurance, and real estate sectors in some disasters 
have experienced more sustained adverse effects (especially in more widespread disasters), while the construction sector often rebounds quickly to a higher level of activity (Ewing et al. 2003b; Kroll et al. 1991).

The effects on labor market outcomes depend on, and often mirror, the broader economic effects of a disaster, including the consequences for business performance in general or small business performance in particular, as well as economic growth. As with labor market outcomes, researchers tend to find short-term negative consequences, along with evidence of even longer-term benefits for economic growth, albeit with sectoral and geographic variation around this aggregate pattern. For example, Webb, Tierney, and Dahlhamer (2000) summarized the findings from a series of studies that collected comparable data on businesses in regions affected by several of the most costly natural disasters in the late 1980s and early 1990s (namely, the 1989 Loma Prieta earthquake, Hurricane Andrew in 1992, the 1993 Midwest floods, and the 1994 Northridge earthquake). The authors concluded that most businesses tend to recover, with some even better off at least in the short term. More favorable outcomes tend to be found for larger businesses, those in better financial condition before the event, and those that experienced less disruption. Again, the sector matters; evidence suggests that construction-related businesses, for example, generally fare well. Webb, Tierney, and Dahlhamer (2002) reported similar findings based on data collected from businesses to assess the longer-term effects of the Loma Prieta earthquake and Hurricane Andrew. Alesch et al. (2001a, 2001b) provided further insights based on studies of small businesses following the Northridge earthquake and other disasters. They concluded that survival depends on individual business characteristics, including commercial insurance coverage and other management techniques that can mitigate exposure and vulnerability to various disasters and allow for a flexible response (e.g., diversified customer base and supply chain, flexible lease provisions). The resiliency and creativity of the business owner was another marker of the ability of a small business to survive and recover.

In terms of the broader economic effects, Skidmore and Toya (2002) postulated that a disaster can stimulate long-term growth through the adaptation of new technology as a result of replacing destroyed capital. Indeed, they found evidence of a long-term positive effect on GDP growth, using cross-national data that are used to model the effect of the number of disasters, controlling for geographical area, on GDP growth. Such aggregate economic benefits, however, may not hold for all disasters. For example, Guimaraes, Hefner, and Woodward (1993) estimated that the unreimbursed wealth loss from Hurricane Hugo in South Carolina in 1989 was not compensated for by the eventual economic gains in some sectors, generating a net negative economic effect. Given the range of experiences following natural disasters, recent research has begun to explore the complex relationship between pre-disaster conditions - including notions of robustness and resiliency, the nature and magnitude of the disaster, and the response to the disaster by various public and private actors - and the resulting post-disaster outcomes (see, e.g., Alesch 2003; Tierney 2003; Tierney and Bruneau 2007).

Compared with research on the labor market and economic effects of disasters, far less attention has been centered on the demographic and health effects of disasters in the United States, in part because of data limitations. ${ }^{2}$ For example, to gauge the demographic impact of Hurricane Andrew, Smith and McCarty (1996) fielded their own survey of nearly 6,000 residents in the affected communities, collecting information on how the hurricane affected them and their immediate neighbors (a type of network sampling to ensure that persons who may have left the area were captured in the survey). Schuster et al. (2001) provided another example of specialized data collection, in this case in response to the September 11, 2001, terrorist attacks. Three to five days after the traumatic events of that day, the study team

2. Examples of studies in low-income countries include Sastry (2002) and Frankenberg, McKee, and Thomas (2005). 
fielded a nationally representative telephone survey of 560 adults to assess the mental health effects for the interviewees and their children, both for those in the immediate area, as well as for those in other parts of the country who experienced the event through television and in other ways. Other demographic analyses have been able to rely on extant sources of data, such as those of Rodgers, St. John, and Coleman (2005), who used birth records data to estimate a positive fertility response to the Oklahoma City bombing in 1995.

Most recently, a literature has emerged that examines the effects of Hurricane Katrina, drawing upon traditional data sources used to study disasters along with data collected specifically to assess Katrina's effects. The combination of low-lying coastal communities vulnerable to storm surges and flooding, a socioeconomically vulnerable population, and poorly prepared national, state, and local institutions produced a devastating combination of lost lives, property damage, and human displacement (Cutter et al. 2006). Much of the immediate research focus was on the short-term population shifts resulting from the massive out-migration from New Orleans and other parts of the Gulf Coast region using census data (see, e.g., Frey and Singer 2006) or specialized surveys (see, e.g., Elliott and Pais 2006; Sastry 2009).

The addition of several questions to the monthly CPS conducted by the U.S. Census Bureau (discussed in more detail below) further supports analysis of the labor market effects of Katrina. The short-term effects on employment were described in the August 2006 Monthly Labor Review based on several data sources, including the CPS through June 2006 (Brown, Mason, and Tiller 2006; Clayton and Spletzer 2006; Garber et al. 2006; Kosanovich 2006). These studies show that in the months immediately following Katrina, employment declined in the affected states and counties and varied by region, industry, and evacuation status. The potential for labor market effects was largest in Louisiana, with an estimated $17 \%$ of the state's employment in FEMA-designated damage zones, compared with 5\% for Mississippi. The damages in Alabama and Florida were smaller still. Other work shows disproportionate negative effects on labor market outcomes for black workers compared with whites (Elliott and Pais 2006).

Subsequent research by Groen and Polivka (2008a, 2008b) used data from the CPS through October 2006 to look at longer-term effects for those who evacuated on three outcomes: labor force participation rate, employment-population ratio, and unemployment rate. Using a difference-in-difference methodology, they found that evacuees fared worse on each outcome, although the negative effects decreased over time. Those evacuees who did not return to their pre-Katrina counties fared even worse, in part because of selectivity in who returned and who did not, but also because they came from areas that had greater housing damage. Vigdor (2007) also used the CPS and a difference-in-difference methodology to examine hours worked, employment, earnings, total income, transfer income, and self-employment income for evacuees versus non-evacuees, and returnees versus non-returnees. He, too, found short-term negative effects for evacuees who return but found more persistent negative effects for evacuees who do not return. The results also indicate that the income losses from lower employment among non-returnees were partially replaced by transfer income and self-employment income.

This article complements and extends the analyses by Groen and Polivka and Vigdor, using the same CPS data, with a more extensive examination of self-employment as a key labor market outcome. ${ }^{3}$ Our focus on the effect of Katrina on self-employment draws on another literature that addresses the factors that promote entrepreneurship. A natural disaster may encourage movements into self-employment by offering new opportunities for entrepreneurship, but it may also be a second best option for workers displaced from wage

3. Although self-employment is not a focus of their study, Groen and Polivka (2008b) reported that selfemployment rates were higher among employed evacuees and employed evacuees who did not return compared with pre-Katrina rates in the affected areas. 
and salary work. Blanchflower and Oswald (1998) and Manser and Picot (1999) argued that people are pushed into self-employment by poor job prospects in the wage and salary sector. Moore and Mueller (2002) found that Canadian workers are more likely to become self-employed the longer the spell of joblessness, when unemployment benefits are not collected between jobs, and when the reason for job loss is an involuntarily separation. Self-employment rates have also been found to rise with increases in local or national unemployment rates, at least for some groups such as women (Schuetze 2000; Simpson and Sproule 1998), but this finding is not universal (Blanchflower 2000). Although some of the aforementioned studies have considered the effect of natural disasters on small business activity, self-employment behavior at the level of the individual entrepreneur has generally not been a subject of prior research.

The micro-level CPS data, with the addition of questions that support analysis of evacuees regardless of where they relocated, provide an opportunity to examine the implications of Hurricane Katrina for key labor market outcomes, including self-employment, while also accounting for demographic characteristics. In the analyses that follow, we first conduct a time-series analysis of labor market outcomes, including labor force participation, employment, unemployment, and self-employment rates, from late 2003 to late 2006. Using quarterly data, we can determine the extent to which aggregate labor market outcomes at the state level returned to their pre-Katrina levels more than a year after the natural disaster. Second, we examine the same labor market outcomes for those who evacuated from the Katrina-affected states, considering differences among those who return and those who do not, as well as differences by geography and over time. Third, we extend the descriptive analyses to a regression framework to estimate the labor market effects of Katrina after accounting for individual characteristics and other labor market variables that may explain differences in labor market outcomes across groups, geographic regions, and over time.

\section{DATA}

We use data from the CPS, a monthly survey of 60,000 households conducted by the U.S. Census Bureau for the Bureau of Labor Statistics. This survey provides data on the civilian, noninstitutional population aged 15 years and older, including information on labor force outcomes such as labor force participation, employment, unemployment, and class of worker (e.g., wage and salary versus self-employment). Personal characteristics of respondents are also collected, including sex, age, race/ethnicity, marital status, and educational attainment. In terms of geography, the CPS is most suited to estimating labor market outcomes at the state or national level. ${ }^{4}$

We use the CPS labor market data to measure the following labor market outcomes for prime-age individuals (aged 25 to 64), all measured as percentages:

1. Labor force participation rate: the number of persons aged 25 to 64 in the labor force (those employed plus those unemployed) divided by the population aged 25 to 64 ;

2. Employment rate, also called the employment-to-population ratio: the number of persons aged 25 to 64 employed divided by the population aged 25 to 64 ;

3. Unemployment rate: the number of persons aged 25 to 64 not working but actively looking for work divided by the number of persons aged 25 to 64 in the labor force;

4. Garber et al. (2006) used establishment data and Brown et al. (2006) used Local Area Unemployment Statistics data to assess labor market outcomes following Katrina at a finer level of geography. These data do not have information on worker characteristics, as is the case with the CPS. At the same time, the sample sizes in the CPS are usually not sufficient for analyses of local labor market outcomes. 
4. Self-employment rate: the number of employed persons aged 25 to 64 who report that they are self-employed in an incorporated or unincorporated business divided by the number of employed persons aged 25 to 64 .

The CPS data collection efforts experienced many operational and analytic challenges in the specific geographic areas affected by Hurricane Katrina (Cahoon et al. 2006). Fortunately, the next interview round in September 2005 was scheduled for three weeks postKatrina, which allowed for some adjustments to be made. For example, destroyed housing units are usually not retained in the sample for possible reinterview in subsequent months, but an exception was made in the hurricane-affected areas through December 2005. This meant that sampled addresses that were vacant were revisited in subsequent months even if the dwelling unit was damaged or destroyed, and interviews were conducted with individuals living in temporary structures, such as a trailer on their property. Even with these adjustments, there was a substantial decline in the number of households interviewed in the months immediately following Hurricane Katrina. For example, in Louisiana, the number of households interviewed declined by 36\% from August to September 2005 (Cahoon et al. 2006). Cahoon et al. (2006) described the adjustments made to the sample weights using information from the U.S. Postal Service's National Change of Address database and demographics from the 2000 census to account for the complications created by nonresponse because of interstate migration.

Important for this study is a series of questions added to the monthly CPS to identify people evacuated from their home because of Hurricane Katrina throughout the United States. Starting with the October 2005 survey, all CPS households were queried about anyone living or staying in their residence who had to evacuate - even temporarily-where he or she was living in August because of Hurricane Katrina, who it was, and where he or she was living in August prior to the hurricane warning. Information on labor force status and other questionnaire items were collected for these "evacuees" in the same manner as for other household members. The special Katrina-related questions were included in the monthly CPS through October 2006.

We use this information, in combination with state identifiers, to classify all prime-age CPS respondents into one of four mutually exclusive categories:

1. Non-evacuee in non-Katrina state: currently living outside a Katrina-affected state (Alabama, Florida, Louisiana, and Mississippi) and not an evacuee;

2. Non-evacuee in Katrina state: currently living in a Katrina-affected state and not an evacuee;

3. Returnee evacuee: evacuated from a Katrina-affected state and currently living in the same state from which he or she evacuated (although not necessarily the same address);

4. Non-returnee evacuee: evacuated from a Katrina-affected state and currently not living in the same state from which he or she evacuated.

Table 2 shows the sample sizes for these four groups pooled from the November 2005 through the October 2006 CPS. ${ }^{5}$ For the second and third groups, we also disaggregate respondents into the four Katrina-affected states of current residence.

In the analyses that follow, we employ the CPS as a cross-sectional survey. Although there is a longitudinal component to the CPS, most evacuees who did not return to their original location were not found when they would have been scheduled to later rejoin the

5. Although the Katrina-related questions first appeared in the October 2005 survey, they were not included in the standard CPS public-use files until the November 2005 file. 
Table 2. Respondent Classification by Evacuee Status and State (number of observations)

\begin{tabular}{lc}
\hline Evacuee Status & $\begin{array}{c}\text { Number of } \\
\text { Observations }\end{array}$ \\
\hline Non-evacuee in non-Katrina state & 803,310 \\
Non-evacuee in Katrina state & 58,875 \\
Returnee evacuee & 2,128 \\
Non-returnee evacuee & 571 \\
Total & 864,884 \\
\hline
\end{tabular}

Note: The sample is the noninstitutionalized population aged 25-64. Katrina states are Alabama, Florida, Louisiana, and Mississippi.

Source: Authors' calculations using monthly CPS data from November 2005 to October 2006.

sample because the CPS samples housing units not individuals. ${ }^{6}$ Thus, we do not attempt to measure pre-Katrina labor market outcomes for our sample.

\section{RESULTS}

In this section, we present results from three interrelated analyses of the labor market effects of Hurricane Katrina. First, we focus on time trends in the four labor market indicators for the Katrina states and all other states from September 2003 to November 2006, extending state-specific time series results provided by Brown et al. (2006), using BLS Local Area Unemployment Statistics (LAUS) and CPS data. The time-trend analysis begins in 2003 to capture pre-Katrina trends and employment effects of Hurricane Ivan in September 2004, one year earlier. Second, we examine time trends in the same four labor market outcomes over time by evacuee status for the period that these data are available (November 2005 to October 2006), disaggregating our sample into the four groups listed earlier. ${ }^{7}$ Third, we model the various labor market outcomes by evacuation status, with controls for demographic characteristics, state characteristics, and interactions of evacuation status by current state and time. These last two analyses extend work by Vigdor (2007) and Groen and Polivka (2008a, 2008b) and allow us to determine the effects on labor market outcomes for individuals who were affected and those who were unaffected by Hurricane Katrina, with and without controls for other factors that might explain variation in the outcomes of interest.

\section{Aggregate Trends in Labor Market Outcomes: 2003-2006}

Figures 1-4, respectively, report time-series results for the four labor market outcomes of interest for the prime age population: labor force participation rate, employment rate, unemployment rate, and self-employment rate. In each table, results are shown for the United States as a whole, for the five major census regions (Northeast, Midwest, Atlantic, South, and West), and for the four Katrina-affected states (Alabama, Florida, Louisiana,

6. Households in the CPS sample are interviewed for four months, leave the survey sample for eight months, and then reenter the same for four additional months. See Vigdor (2007) for a discussion of the issues with trying to track the individuals who were in the CPS prior to Katrina and who subsequently evacuated.

7. We considered the relevance of CPS labor force concepts for evacuees and concluded that the survey definitions will capture their status accurately. The definition of employed includes work during the reference week of one hour or more, work in one's own business, unpaid work of more than 14 hours, or being with a job but not working because of vacation or bad weather. Unemployed is defined as no employment during the reference week but being available for work and making specific efforts to find work in the past four weeks. Not in the labor force is defined as neither employed nor unemployed. Respondents displaced by a hurricane with one month or more of not actively seeking work (resettling) would be classified as not in the labor force. 
Figure 1. Quarterly Labor Force Participation Rate by Region/State: 2003 Q4 Through 2006 Q4

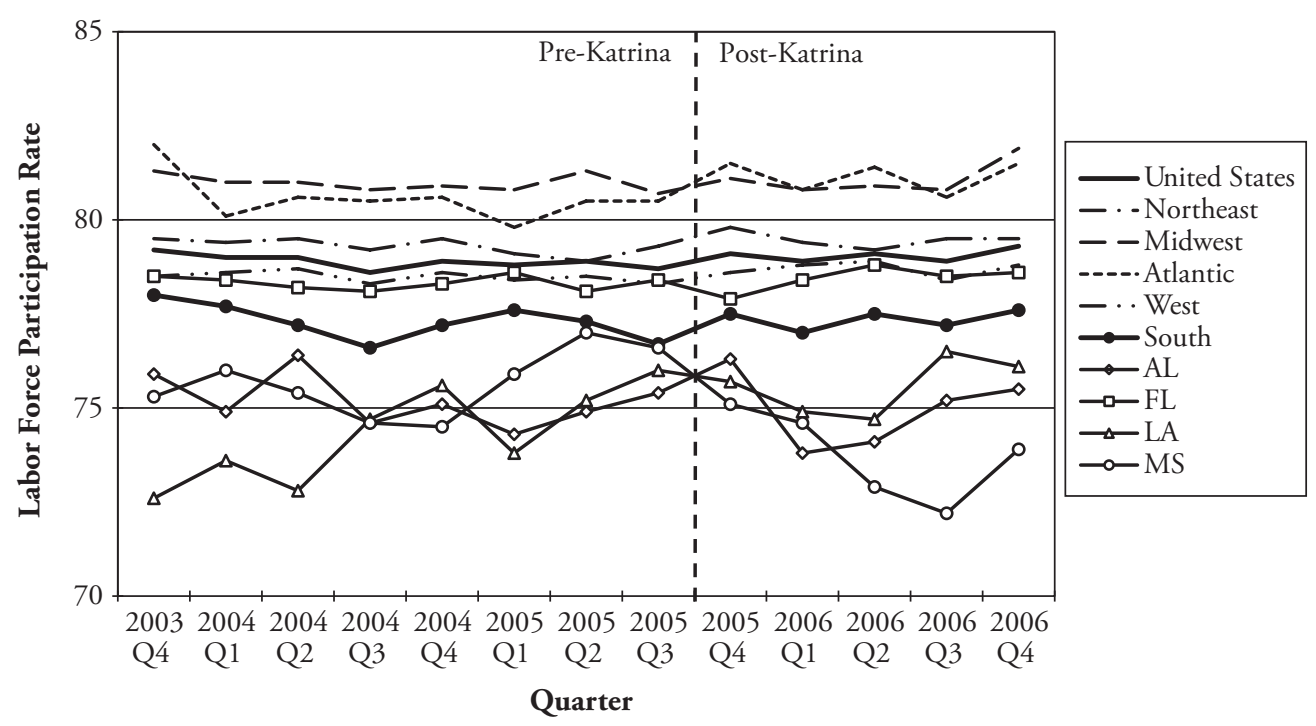

Notes: The sample is the noninstitutionalized population aged 25-64. Results are weighted percentages, not seasonally adjusted. Q1 = December-February, Q2 = March-May, Q3 = June-August, and Q4 = September-November.

Source: Authors' calculations using monthly CPS data from September 2003 to November 2006.

and Mississippi). The data points are provided in Table A1 in the appendix (http://www .soc.duke.edu/resources/demography). The data points are based on pooled data over three monthly surveys (i.e., quarterly data), from two years before Katrina to one year after. Quarters are defined relative to the timing of Hurricane Katrina, which occurred in August, rather than the usual division of the calendar year. Thus, Quarter 4 (Q4) runs from September to November, the first three full months after Katrina made landfall. Quarter 1 (Q1) is from December to February, Quarter 2 (Q2) is from March to May, and Quarter 3 (Q3) is from June to August. A dashed vertical line separates the pre-Katrina quarters from the post-Katrina quarters. All labor market outcomes reported in Figures 1-4, measured as rates and multiplied by 100 for interpretation as percentages, are based on weighted data, but they are not seasonally adjusted.

As seen in Figures 1 and 2, the national time trend shows that the labor force participation rate and the employment rate were both relatively stable over the period covered by the data. Prior to Katrina, both rates were lower in the South compared with the other four regions; and with the exception of Florida, the Katrina states had lower rates than the group of Southern states. In the post-Katrina period for Louisiana, the hardest hit state, there is some evidence of a very small short-term decline in the labor force participation and employment rates. However, one year after the hurricane (2006 Q4), the labor force participation rate was 3.5 percentage points higher than it was in the quarter before the storm (2005 Q3), and the employment rate was somewhat higher, too. Although Alabama shows a similar pattern of a short-term decline followed by recovery, Mississippi did not fare as well. Both the labor force participation rate and employment rate were below the pre-Katrina level by several percentage points one year after the storm. In Florida, the state with relatively smaller damages, there was only a modest one-quarter dip followed by a rebound. 
Figure 2. Quarterly Employment Rate by Region/State: 2003 Q4 Through 2006 Q4

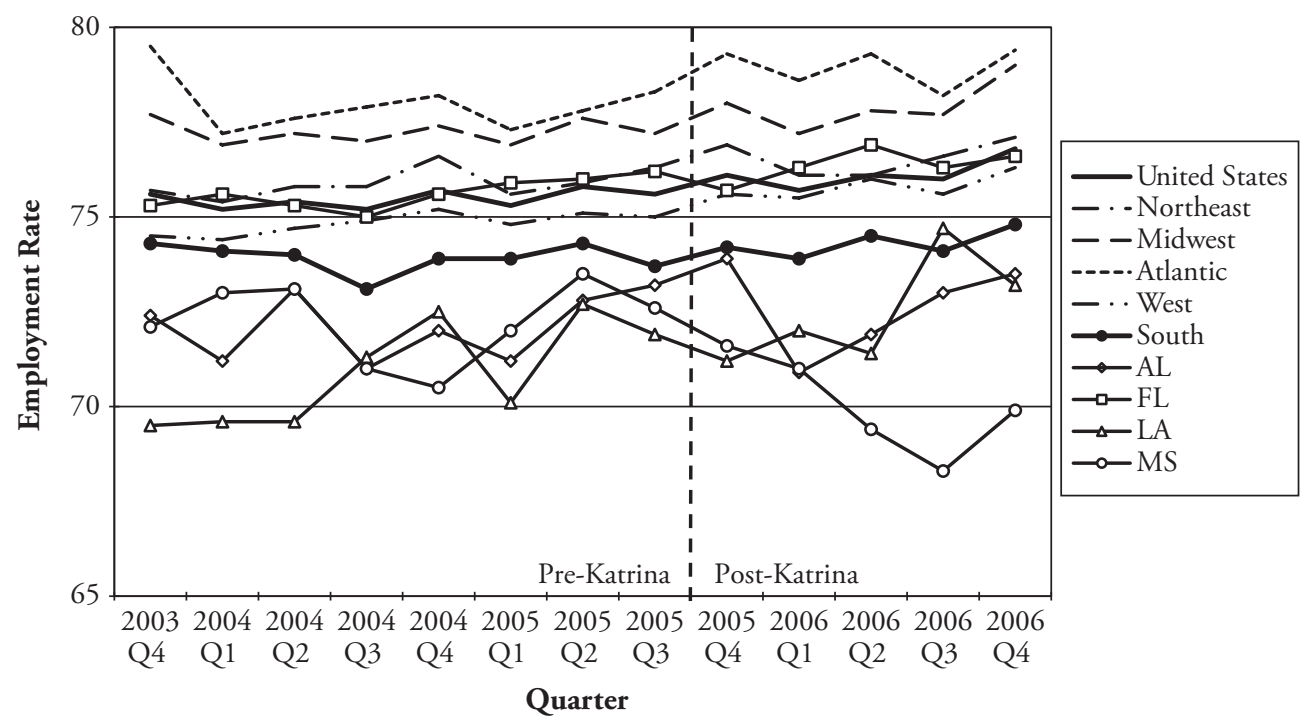

Notes: The sample is the noninstitutionalized population aged 25-64. Results are weighted percentages, not seasonally adjusted. Q1 = December-February, Q2 = March-May, Q3 = June-August, and Q4 = September-November.

Source: Authors' calculations using monthly CPS data from September 2003 to November 2006.

The time trends in the unemployment rate are more complex, as seen in Figure 3. At the national level, the pattern is one of a declining unemployment rate over time. Likewise, Alabama's unemployment rate was on a downward trend until Katrina. The state then experienced an increase in the percentage unemployed in the first two quarters following the hurricane. The percentage of the labor force unemployed was slightly below the pre-Katrina level as of 2006 Q4. Louisiana also experienced an increase in the unemployment rate postKatrina, but only for one quarter and then just one-half percentage point. By the fourth quarter of 2006, the percentage unemployed in Louisiana was 0.4 percentage points lower than in 2003 Q4. In contrast, there is no discernable change in unemployment in Florida following Katrina. Mississippi's unemployment rate dipped slightly below the pre-Katrina level for three quarters and then increased in the last two quarters covered by the data.

Time trends in the percentage of workers that are self-employed are reported in Figure 4. Nationwide, the self-employment rate was relatively stable over the period analyzed, at about $12 \%$ of employed workers. In Alabama, the percentage of workers in self-employment was below the national average in 2003, declined slightly over time, and appears to have been largely unaffected by Katrina. ${ }^{8}$ In most of the quarters reported in Figure 4, workers in Florida were more likely to be self-employed compared with workers in other Katrina states and in the nation as a whole. There were slight fluctuations over time, including a small increase in the first few quarters after Katrina. In Louisiana,

8. The decline from 2003 Q4 to 2006 Q4 is largely driven by the percentage of women self-employed, which fell 3.5 percentage points during this period (evident before Katrina, and thus we do not attribute this drop to Katrina). 
Figure 3. Quarterly Unemployment Rate by Region/State: 2003 Q4 Through 2006 Q4

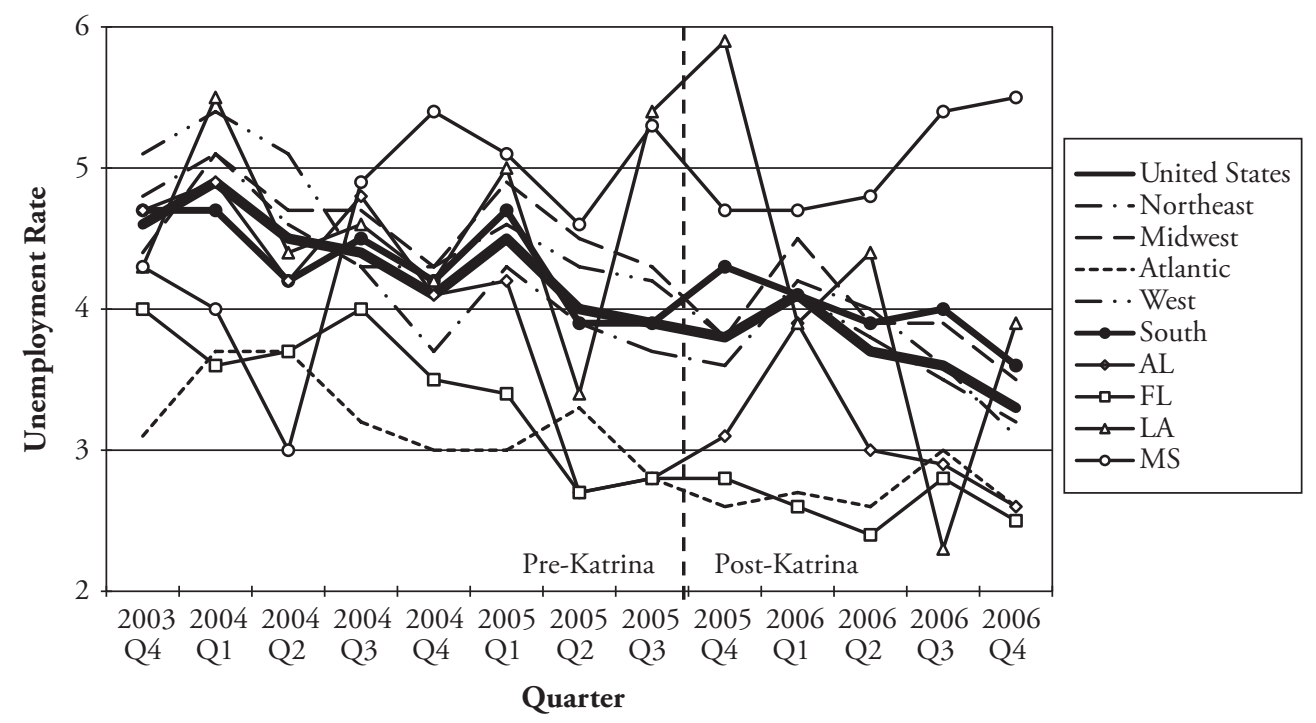

Note: The sample is the noninstitutionalized population aged 25-64. Results are weighted percentages, not seasonally adjusted. Q1 = December-February, Q2 = March-May, Q3 = June-August, and Q4 = September-November.

Source: Authors' calculations using monthly CPS data from September 2003 to November 2006.

the self-employment rate was generally increasing in the post-Katrina quarters, reversing an earlier downward trend. By 2006 Q4, the percentage of workers self-employed in Louisiana was approximately 1 percentage point higher than in 2003 Q4. In Mississippi, self-employment fluctuated more over time than the other Katrina states in the quarters before and after Katrina, so it is difficult to attribute any particular increase or decrease to the hurricane. Interestingly, the self-employment rates for three of the Katrina states (Alabama is the exception) were the same as the national average - or at most, 0.9 percentage points above it-as of 2003 Q4, but the percentage of workers self-employed in those three states was 1.0 to 1.5 percentage points higher than the national average by 2006 Q4. These patterns may be due to a changing mix of the population in the Katrina-affected states because of the post-Katrina migration of disadvantaged workers who are less likely to be self-employed, or they may be due to movements into self-employment among the population that remains or returns. Multivariate models, discussed below, will help disentangle these effects by controlling for observable characteristics of workers at different time periods.

For the most part, these findings are consistent with the prior research on the aggregate labor market effects of natural disasters discussed earlier and with analyses of Hurricane Katrina based on other data sources (Kosanovich 2006). With the exception of Mississippi, within one year, labor force participation and employment rates returned to or exceeded levels experienced before the hurricane. Likewise, any increase in the unemployment rate post-Katrina dissipated within a quarter or two, so that the percentage of labor force participants unemployed in 2006 Q4 was equal to that pre-Katrina, again with the exception of Mississippi. The trends in self-employment rates following Hurricane Katrina, or even after 
Figure 4. Quarterly Self-employment Rate by Region/State: 2003 Q4 Through 2006 Q4

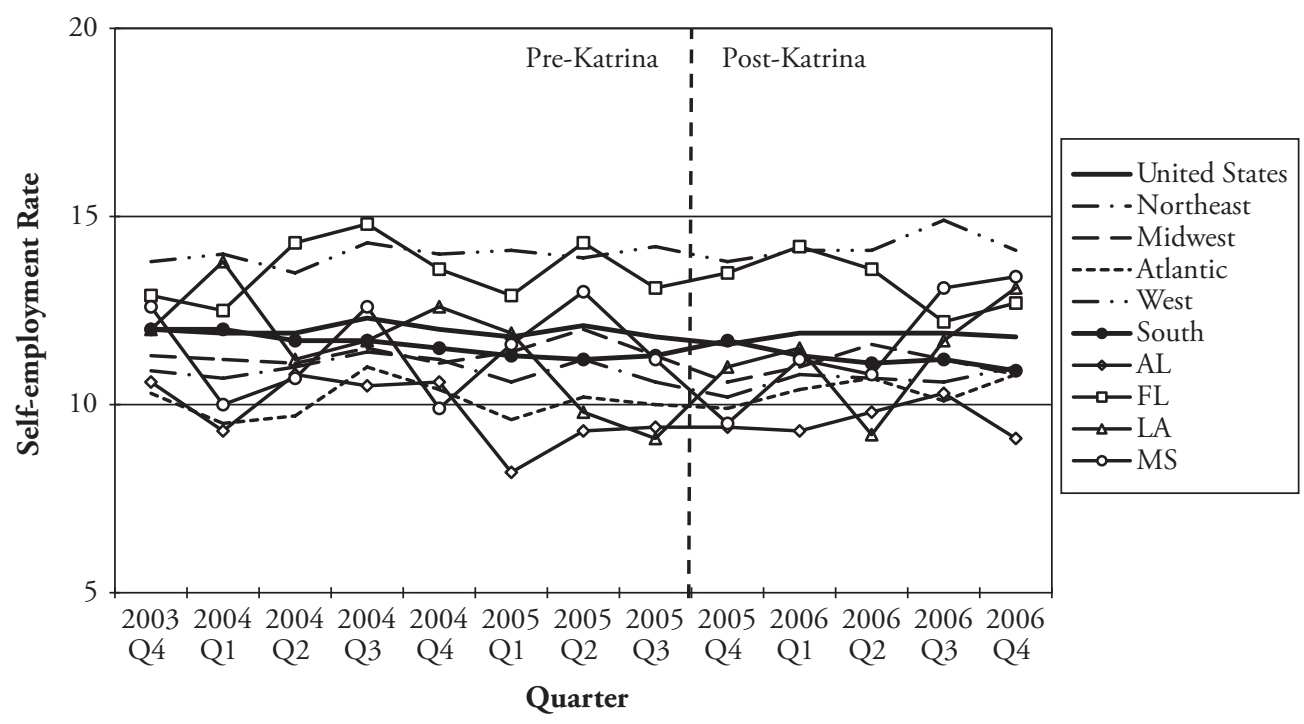

Notes: The sample is the noninstitutionalized population aged 25-64. Results are weighted percentages, not seasonally adjusted. Q1 = December-February, Q2 = March-May, Q3 = June-August, and Q4 = September-November.

Source: Authors' calculations using monthly CPS data from September 2003 to November 2006.

other natural disasters, have not been as thoroughly documented. In contrast to the stable self-employment rate at the national level, the percentage of workers self-employed was slightly higher in Q4 2006 than in Q4 2003 for Louisiana and Mississippi, unchanged in Florida, and lower in Alabama. This indicates that self-employment remained an important component of labor market activity following the hurricane, suggesting either resiliency on the part of existing businesses or the need and/or opportunity to start new businesses in the wake of the disaster.

\section{Trends in Labor Market Outcomes by Evacuee Status: November 2005- October 2006}

To gain further insight into the labor market effects of Katrina, we use the information collected in the CPS from November 2006 to October 2006 that allow us to identify Katrina evacuees. In general, compared with non-evacuees in non-Katrina states or even nonevacuees in Katrina states, we would expect evacuees, because of their displacement, to face a greater likelihood of unfavorable labor market outcomes, such as being out of the labor force or unemployed. If workers are "pushed" into self-employment by bad economic prospects in the wage and salary market, we might also see higher rates of self-employment among evacuees. On the other hand, evacuees may find that displacement and local economic disruptions open up favorable opportunities in entrepreneurship and are therefore "pulled" into self-employment.

As noted earlier, among this group of evacuees, we can also identify who is a returnee at any point in time (to their same pre-Katrina state) and who is not a returnee. We might expect returnees to have more labor market success because they have the ability to return 
Table 3. Evacuees Returning to Pre-Katrina State (percentages)

\begin{tabular}{lcc}
\hline Evacuee Status & $\begin{array}{c}\text { First 6 Months } \\
(11 / 05-04 / 06)\end{array}$ & $\begin{array}{c}\text { Second 6 Months } \\
(05 / 06-10 / 06)\end{array}$ \\
\hline Returnees & 72.8 & 83.8 \\
Non-returnees & 27.2 & 16.2 \\
Total & 100.0 & 100.0 \\
Unweighted $N$ & 1,226 & 1,473 \\
\hline \multicolumn{2}{c}{ Notes: The sample is the noninstitutionalized population aged 25-64. Katrina } \\
states are Alabama, Florida, Louisiana, and Mississippi. Results are weighted percent- \\
ages, not seasonally adjusted. Returnees are those who currently reside in the same \\
state they lived in before Katrina but not necessarily at the same address. \\
Source: Authors' calculations using monthly CPS data from November 2005 to \\
October 2006.
\end{tabular}

to their original state, either because their economic losses were smaller or they have a larger support network (such as family and friends) to support their return. On the other hand, those who do not return may make that choice because their outcomes are better in their new location compared with what they could attain were they to return. We might also expect outcomes for these groups to vary over time, with those who return soon after the hurricane facing fewer barriers to resuming their pre-Katrina life and those who remain as non-returnees facing the greatest barriers. On the other hand, if those who remain in their new location do so because their economic prospects have improved, the selection mechanism may have the opposite effect.

To examine these issues, we use the CPS data from November 2005 to October 2006 to examine the four labor market outcomes by evacuee status and state (being in one of the Katrina-affected states or not). We also look at outcomes for the first six months in the time interval (November 2005 to April 2006) and the second six months (May 2006 to October 2006) to determine whether the patterns differ over time. As seen in Table 3, in the first six months following Hurricane Katrina, $73 \%$ of evacuees had returned to their pre-Katrina state; within another six months, a total of $84 \%$ had returned. Returnees did not necessarily return to the same address. According to Kosanovich (2006), by June 2006, 60\% of evacuees had returned to their pre-Katrina address, based on a sample of respondents aged 16 and older.

Tables 4 and 5 report on the four labor market outcomes for prime-age adults in the four mutually exclusive groups defined earlier based on evacuation status and residence in a Katrina-affected state. In addition, we report outcomes for the U.S. total prime-age population and also combine the two groups of evacuees (i.e., reporting the average for returnees and non-returnees).

Consider first the labor force participation and employment rates reported as percentages in Table 4. For the United States as a whole, and non-evacuees in non-Katrina states, the outcomes are similar and show no change over the two six-month intervals. Non-evacuees in Katrina states were less likely to participate in the labor force or be employed than the United States as a whole, but there was also no change over time. In contrast, evacuees were less likely to participate in the labor force or be employed than non-evacuees, and their outcomes improved over the two six-month intervals. Moreover, outcomes were considerably less favorable, but also improved over time, for non-returnees compared with returnees. For example, from November 2005 to October 2006, 71\% of evacuees participated in the labor force, while $79 \%$ of prime-age individuals from non-Katrina states and $77 \%$ of non-evacuees from Katrina states participated in the labor force. Among evacuees, the lowest rates were among the non-returnees (59\% versus 74\%). Evacuees' labor force participation increased substantially over time from $68 \%$ to $74 \%$ but was still below that of 
Table 4. Labor Force Participation and Employment Rates by Evacuee Status (percentages)

\begin{tabular}{|c|c|c|c|c|c|c|}
\hline \multirow[b]{3}{*}{ Evacuee Status } & \multicolumn{3}{|c|}{ Labor Force Participation } & \multicolumn{3}{|c|}{ Employment } \\
\hline & $\begin{array}{c}\text { First } 6 \\
\text { Months, } \\
11 / 05-\end{array}$ & $\begin{array}{c}\text { Second } 6 \\
\text { Months, } \\
05 / 06-\end{array}$ & $\begin{array}{l}\text { All } 12 \\
\text { Months, } \\
11 / 05-\end{array}$ & $\begin{array}{l}\text { First } 6 \\
\text { Months, } \\
11 / 05-\end{array}$ & $\begin{array}{l}\text { Second } 6 \\
\text { Months, } \\
05 / 06-\end{array}$ & $\begin{array}{c}\text { All } 12 \\
\text { Months, } \\
11 / 05-\end{array}$ \\
\hline & $04 / 06$ & $10 / 06$ & $10 / 06$ & $04 / 06$ & $10 / 06$ & $10 / 06$ \\
\hline U.S. Total & 79.0 & 79.0 & 79.0 & 75.9 & 76.3 & 76.1 \\
\hline $\begin{array}{l}\text { Non-evacuee, } \\
\text { Other State }\end{array}$ & 79.2 & 79.3 & 79.2 & 76.1 & 76.5 & 76.3 \\
\hline $\begin{array}{l}\text { Non-evacuee, } \\
\text { Katrina State }\end{array}$ & 77.1 & 77.2 & 77.2 & 74.7 & 75.1 & 74.9 \\
\hline All Evacuees & 67.6 & 73.8 & 70.9 & 59.5 & 66.4 & 63.2 \\
\hline Returnees & 72.5 & 75.4 & 74.1 & 68.0 & 71.5 & 70.0 \\
\hline Non-returnees & 54.0 & 66.0 & 59.0 & 35.8 & 41.0 & 38.0 \\
\hline
\end{tabular}

Notes: The sample is the noninstitutionalized population aged 25-64. Katrina states are Alabama, Florida, Louisiana, and Mississippi. Results are weighted percentages, not seasonally adjusted. Returnees are those who currently reside in the same state they lived in before Katrina but not necessarily at the same address.

Source: Authors' calculations using monthly CPS data from November 2005 to October 2006.

non-evacuees. Non-returnees' labor force participation increased even more dramatically over time from $54 \%$ to $66 \%$. The difference in employment between non-returnees and returnees is even more striking: $38 \%$ versus $70 \%$ over the 12 -month period.

A similar picture emerges for unemployment shown in the first set of columns in Table 5. Here the national pattern and that for non-evacuees is declining unemployment over the two six-month intervals. In contrast, evacuees had unemployment rates about three times the national average at each of the time intervals shown (11\% compared with $4 \%$ over 12 months). Even more striking are the considerably higher levels of unemployment for non-returnees compared with returnees: nearly $36 \%$ compared with $6 \%$. Notably, like the national pattern, unemployment declined for returnees over time, but it increased for non-returnees. This pattern for non-returnees may reflect individuals who were initially categorized as out of labor force or employed (may not have been working because of weather-related absence) in the first six-month interval, later being classified unemployed as they begin to search actively for work in a new location. Alternatively, this pattern may reflect the changing composition of non-returnees over time as the most successful evacuees who are able to return make the transition from being "non-returnees" to "returnees."

Finally, Table 5 shows results for self-employment among employed workers. Here again, the percentage of workers self-employed was the same for the United States as a whole and for non-evacuees in either Katrina or non-Katrina states. There was also no change over the two six-month intervals in self-employment rates for these populations. Among evacuees, the percentage of workers self-employed was higher for returnees than non-returnees viewed over the entire 12-month interval (13\% versus 9\%). However, this difference obscures substantial differences over time in self-employment rates among evacuees. For the first six-month interval, returnees were more likely to be self-employed than any other group (15\%). The group of evacuees who owned businesses in Katrinaaffected states apparently have a strong incentive to return quickly, or some returnees take up self-employment. After one year, the percentage of working returnees self-employed was the same as non-evacuees in Katrina and non-Katrina states. Non-returnees had low rates of self-employment in the first six months, beginning November 2005 (5\%), and had the highest rates one year later (14\%). Consistent with explanations found in the literature, 
Table 5. Unemployment and Self-employment Rates by Evacuee Status (percentages)

\begin{tabular}{|c|c|c|c|c|c|c|}
\hline \multirow[b]{2}{*}{ Evacuee Status } & \multicolumn{3}{|c|}{ Unemployment } & \multicolumn{3}{|c|}{ Self-employment } \\
\hline & $\begin{array}{c}\text { First } 6 \\
\text { Months, } \\
11 / 05- \\
04 / 06\end{array}$ & $\begin{array}{c}\text { Second } 6 \\
\text { Months, } \\
05 / 06- \\
10 / 06\end{array}$ & $\begin{array}{c}\text { All } 12 \\
\text { Months, } \\
11 / 05- \\
10 / 06\end{array}$ & $\begin{array}{c}\text { First } 6 \\
\text { Months, } \\
11 / 05- \\
04 / 06\end{array}$ & $\begin{array}{c}\text { Second } 6 \\
\text { Months, } \\
05 / 06- \\
10 / 06\end{array}$ & $\begin{array}{c}\text { All } 12 \\
\text { Months, } \\
11 / 05- \\
10 / 06\end{array}$ \\
\hline U.S. Total & 4.0 & 3.5 & 3.7 & 11.9 & 11.9 & 11.9 \\
\hline $\begin{array}{l}\text { Non-evacuee, } \\
\text { Other State }\end{array}$ & 4.0 & 3.5 & 3.8 & 11.8 & 11.9 & 11.8 \\
\hline $\begin{array}{l}\text { Non-evacuee, } \\
\text { Katrina State }\end{array}$ & 3.0 & 2.8 & 2.9 & 12.5 & 12.0 & 12.3 \\
\hline All Evacuees & 12.0 & 10.0 & 10.9 & 13.3 & 12.3 & 12.7 \\
\hline Returnees & 6.2 & 5.1 & 5.6 & 15.0 & 12.1 & 13.3 \\
\hline Non-returnees & 33.7 & 38.0 & 35.7 & 4.5 & 13.6 & 8.6 \\
\hline
\end{tabular}

Notes: The sample is the noninstitutionalized population aged 25-64. Katrina states are Alabama, Florida, Louisiana, and Mississippi. Results are weighted percentages, not seasonally adjusted. Returnees are those who currently reside in the same state they lived in before Katrina but not necessarily at the same address.

Source: Authors' calculations using monthly CPS data from November 2005 to October 2006.

non-returnees may find favorable prospects in self-employment in the state where they relocated, or they may not find advantageous opportunities for wage and salary jobs and are instead "pushed" into self-employment.

These tabulations indicate that labor force participation and employment rates of evacuees remained below that of non-evacuees and unemployment rates above that of nonevacuees one year following Hurricane Katrina, with non-returnees experiencing the least favorable labor market outcomes among the evacuees. These patterns are consistent with those reported by Cahoon et al. (2006) based on the CPS data through June 2006, and by Groen and Polivka (2008a, 2008b) using CPS data through October 2006. What has not been previously documented is that the self-employment rate for non-returnees increases over the first year following the hurricane, eventually exceeding the rate for non-evacuees, perhaps because of both push and pull factors.

These differences in labor market outcomes between evacuees and non-evacuees and by type of evacuee (returnee or not) shown in Tables 4 and 5 may result, in part, from differences in the characteristics of the groups. That is, some of the differences in labor market outcomes may have existed before Hurricane Katrina so that composition effects explain some of the patterns we see. Table 6 illustrates select characteristics of the groups we have been examining for the two six-month intervals. The two groups of non-evacuees (non-Katrina and Katrina states) show stable characteristics over time and differences in characteristics reflect demographic differences between southern and non-southern states (e.g., lower levels of education and higher fraction of blacks). Among the two groups of evacuees, the population differences are starker, as are the composition changes over time. ${ }^{9}$ For example, non-returnees are younger, less likely to be married or have a college degree, much more likely to be black, and more likely to be female compared with non-evacuees or returnees. Early returnees are similar to non-evacuees in age and marital status but are more likely to be female and black. Later returnees compared with early returnees are more likely to be male and less likely to have a college degree or higher.

9. Groen and Polivka (2009) documented similar differences in the characteristics of returnees versus nonreturnees, although they did not consider patterns over time. 
Table 6. Characteristics by Evacuee Status, State, and Time (percentages)

\begin{tabular}{|c|c|c|c|c|c|c|c|c|}
\hline \multirow[b]{2}{*}{ Characteristic } & \multicolumn{2}{|c|}{$\begin{array}{c}\text { Non-evacuee, } \\
\text { Other State }\end{array}$} & \multicolumn{2}{|c|}{$\begin{array}{l}\text { Non-evacuee, } \\
\text { Katrina State }\end{array}$} & \multicolumn{2}{|c|}{ Returnee } & \multicolumn{2}{|c|}{ Non-returnee } \\
\hline & $\begin{array}{l}11 / 05- \\
04 / 06\end{array}$ & $\begin{array}{c}05 / 06- \\
10 / 06\end{array}$ & $\begin{array}{c}11 / 05- \\
10 / 06\end{array}$ & $\begin{array}{c}05 / 06- \\
10 / 06\end{array}$ & $\begin{array}{l}11 / 05- \\
04 / 06\end{array}$ & $\begin{array}{c}05 / 06- \\
10 / 06\end{array}$ & $\begin{array}{c}11 / 05- \\
10 / 06\end{array}$ & $\begin{array}{r}05 / 06 \\
10 / 06\end{array}$ \\
\hline Age & 43.5 & 43.6 & 44.0 & 44.2 & 44.5 & 44.0 & 40.6 & 43.3 \\
\hline Male (\%) & 49.2 & 49.2 & 48.5 & 48.4 & 44.5 & 47.4 & 38.2 & 44.8 \\
\hline Married (\%) & 64.8 & 64.3 & 62.3 & 61.0 & 61.7 & 59.2 & 43.3 & 51.7 \\
\hline College or More (\%) & 57.7 & 57.8 & 53.8 & 53.7 & 56.7 & 50.1 & 48.3 & 46.7 \\
\hline Hispanic (\%) & 13.5 & 13.7 & 14.2 & 14.4 & 5.7 & 3.5 & 4.9 & 4.4 \\
\hline Black (\%) & 10.5 & 10.6 & 19.1 & 19.4 & 24.9 & 21.7 & 62.7 & 65.9 \\
\hline White (\%) & 69.0 & 68.8 & 63.8 & 63.4 & 66.5 & 68.6 & 31.6 & 27.3 \\
\hline
\end{tabular}

Notes: The sample is the noninstitutionalized population aged 25-64. Katrina states are Alabama, Florida, Louisiana, and Mississippi. Results are weighted percentages, not seasonally adjusted. Returnees are those who currently reside in the same state they lived in before Katrina but not necessarily at the same address.

Source: Authors' calculations using monthly CPS data from November 2005 to October 2006.

Over time, the non-returnee population becomes older, more likely to be married and male, but the education, racial, and ethnic composition show less change. In other words, evacuees, particularly non-returnees, have characteristics that are generally associated with lower rates of labor force participation and higher rates of unemployment compared with non-evacuees from Katrina and non-Katrina states.

\section{Multivariate Analysis of Labor Force Outcomes by Evacuee Status, State, and Time}

To separate the labor market effects of Hurricane Katrina over time by state and evacuee status, we estimate logistic regression models of the propensity to be in the labor force, employed, unemployed, and self-employed. Our interest is in the estimated differences in these outcomes by evacuee status (non-evacuee in Katrina states, returnee, non-returnee) relative to non-evacuees in non-Katrina states, after controlling for other observable differences between individuals and other macro-economic factors that can affect labor market outcomes. Thus, the models include controls for the demographic characteristics examined in Table 6 (age plus age squared to allow for a nonlinear relationship, sex, marital status, educational attainment, and race/ethnicity) and citizenship status. We also include monthof-year indicators, indicators for the Katrina-affected state where the respondent currently resides (those in non-Katrina states are the reference group), the state-level unemployment rate for the respondent's current state of residence, and the state industrial mix (measured by the percentage of total payroll in 18 sectors). In the first model, we include evacuee status interacted with three time periods (indicators for four-month periods beginning with November 2005); and in a second model, we interact evacuee status with current state for the four Katrina-affected states, with all other states acting as the excluded group. To the extent that the observables do not control for other differences between evacuee groups, such as preferences for work, we interpret our results as measuring the relationship between evacuee status and labor market outcomes but not as measuring how evacuee status affects labor market outcomes.

Our results are best viewed in terms of predicted probabilities, where all characteristics except for evacuee status, time, or state are held constant at the mean value. Figure 5 shows the predicted rates for labor force participation, employment, unemployment, and 
Figure 5. Predicted Probability of Labor Force Participation, Employment, Unemployment, and Self-employment Over Time by Evacuee Status
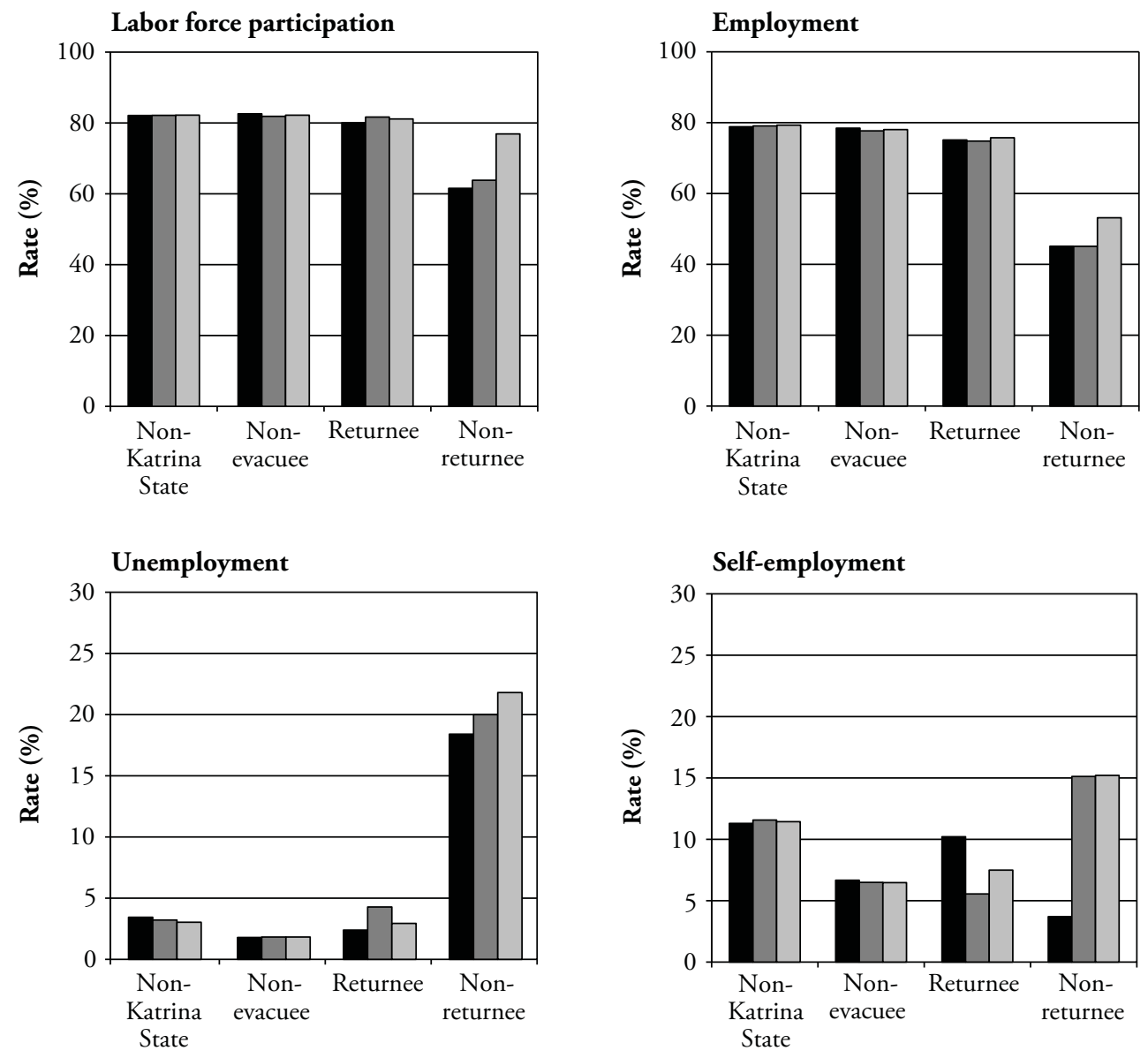

$\mathrm{T} 1 \quad \square \mathrm{T} 2 \quad \square \mathrm{T} 3$

Note: The sample is the noninstitutionalized population aged 25-64. Katrina states are Alabama, Florida, Louisiana, and Mississippi. Returnees are those who currently reside in the same state they lived in before Katrina but not necessarily at the same address. T1 = November 2005-February 2006, T2 = March 2006-June 2006, and T3 = July 2006-October 2006.

Source: Authors' calculations based on multivariate logistic regression model using monthly CPS data from November 2005 to October 2006.

self-employment based on the first model with time and evacuee status interactions; Figure 6 shows the predicted rates based on the second model with state and evacuee status interactions. The logistic regression model results used to generate the two figures are available in Tables A2 and A3 in the online appendix.

In the first three panels of Figure 5, the most striking difference is the substantially worse predicted labor market outcomes for non-returnees compared with either returnees or non-evacuees even after controlling for the demographic and labor market variables in 
the model. Although there was some improvement over time for non-returnees in their labor force participation and employment rates (with differences that were no longer statistically significant by the third period for the labor force participation rate), the unemployment rate actually worsened over time. The percentage of non-returnees unemployed exceeds that for the other groups by more than 15 percentage points (statistically significant in all time periods). There is some indication that returnees had worse outcomes in the first or second time periods (up to eight months after the hurricane), but there are no significant differences between returnees and non-evacuees in the first three labor market outcomes by the third period.

As seen in the fourth panel of Figure 5, the same pattern observed in Table 5 for selfemployment rates among returnees and non-returnees persists even after controlling for the characteristics in the model. Notably, returnees were initially more likely to be selfemployed than either non-evacuees or non-returnees (statistically significant), but by the third period, their self-employment rate was slightly above, albeit not statistically different than, that for non-evacuees. In contrast, the model predicts that only $4 \%$ of employed nonreturnees were self-employed in the first period; but by the second and third periods, this number increased to over $15 \%$. Because of large standard errors, the differences are not significant at standard levels (significant at the 10\% level). Thus, although self-employment may be important initially for returnees, it is less important over time. There is some evidence that it may be most important for non-returnees.

Figure 6 uses the second regression model to show the predicted percentage of nonevacuees (in Katrina states) compared with returnees in the labor force, employed, unemployed, and self-employed, separately by their current Katrina-affected state (which is also the state of evacuation for the returnees). Outcomes are also shown for non-returnees averaged over all non-Katrina states. These predictions are for outcomes averaged over the 12 months from November 2005 to October 2006. In terms of labor force participation, employment, and unemployment, the results indicate that returnees in Alabama and Florida had more favorable outcomes relative to non-evacuees; those in Louisiana and Mississippi show the opposite pattern. Among returnees, those in Florida - and to some extent, those in Alabama-generally fared better than returnees in the other two Katrina-affected states. Consistent with Figure 5, non-returnees had the least favorable outcomes on the first three labor market indicators, all statistically significant differences. Among workers, returnees in Alabama and Florida had higher self-employment rates than their non-evacuee counterparts in the same state.

For many individuals, evacuee status was a choice and was not imposed by authorities. It may be the case that the group that returned is different than non-evacuees in ways that are correlated with labor market outcomes and that these groups are different across states. Thus, we cannot interpret the results in Figures 5 and 6 as the effect of evacuating (and returning) on the various outcomes. That said, our models control for many observable differences at the individual level and state level that we know to be correlated with labor market outcomes. Moreover, our results for labor force participation, employment, and unemployment are consistent with those reported by Groen and Polivka (2008a) using the same CPS data and a difference-in-difference methodology to control for the causal effect of Katrina on these outcomes.

Together, these results show substantially different labor market experiences within the population that evacuated based on who returned and who did not-differences that are not explained by the demographic characteristics of evacuees versus non-evacuees and returnees versus non-returnees. Although evacuees who eventually returned to their preKatrina state experienced some initial negative labor market effects in terms of lower rates of labor force participation and employment and higher rates of unemployment, by one year after the hurricane, outcomes for this group were approaching those for non-evacuees from the Katrina-affected states and those in other parts of the country. There is some evidence 
Figure 6. Predicted Probability of Labor Force Participation, Employment, Unemployment, and Self-employment in the Four Katrina States by Evacuee Status
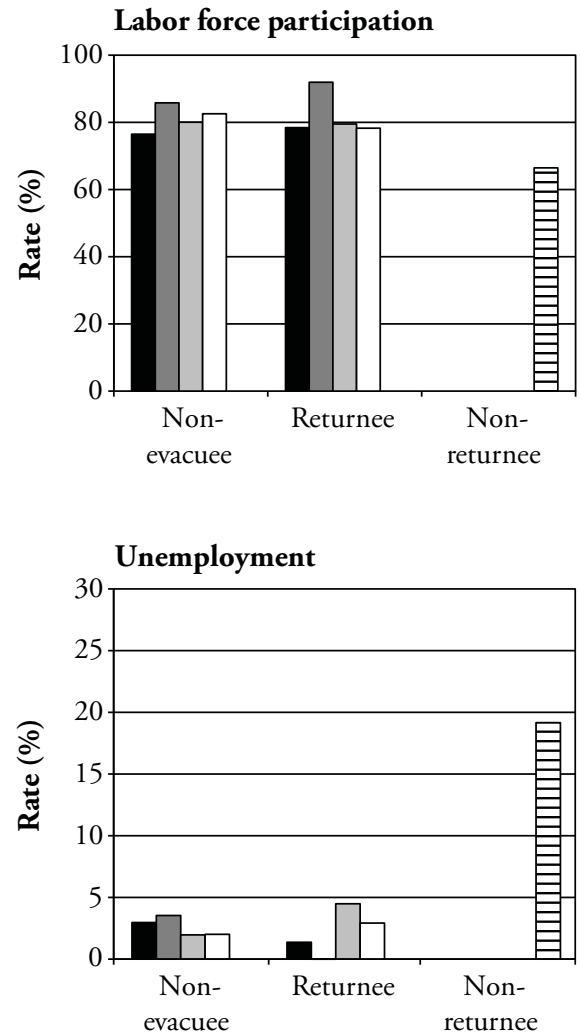
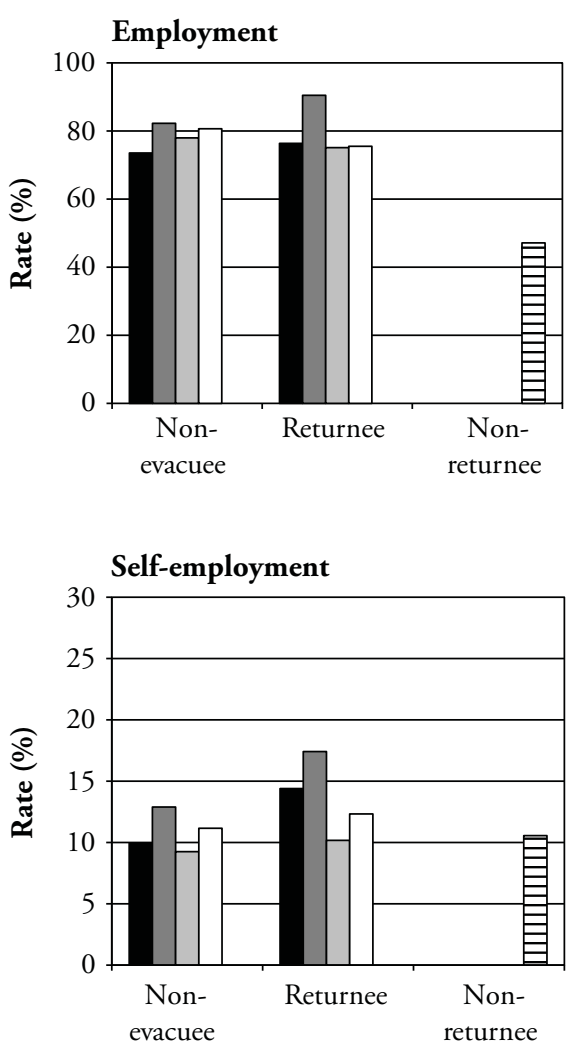

AL $\square$ FL $\square$ LA $\square$ MS 目Other

Notes: The sample is the noninstitutionalized population aged 25-64. Katrina states are Alabama, Florida, Louisiana, and Mississippi. Returnees are those who currently reside in the same state they lived in before Katrina but not necessarily at the same address.

Source: Authors' calculations based on multivariate logistic regression model using monthly CPS data from November 2005 to October 2006.

that returnees were also more likely to be self-employed up to one year after the storm compared with those who did not evacuate. In contrast, the group of non-returnees faced substantially worse labor market outcomes in the immediate aftermath of the storm, with only modest recovery, if at all, up to one year later. Notably, among non-returnees who were working, self-employment was more prevalent than among non-evacuees or returnees, an effect that appears to strengthen over time.

\section{CONCLUSION}

Given the magnitude of the economic damages imposed by Hurricane Katrina, the enormous number of displaced persons, and the geographic reach of the storm's impact, it is 
important to understand the labor market consequences of the natural disaster, particularly for those who left their homes, even temporarily. The addition of questions to the monthly CPS for one year following the storm provides an opportunity-one not available with other similar events - to examine labor market outcomes for those in the affected areas, as well as those who relocated to other parts of the country. The CPS microdata also support the inclusion of demographic controls to account for differences among evacuees and nonevacuees and returnees and non-returnees.

When used to examine aggregate labor market outcomes pre- and post-Katrina for affected and unaffected states, the CPS confirms a pattern that has been found in the wake of other disasters: relatively short-term negative outcomes followed by eventual recovery. With the CPS, we examine effects up to one year following Katrina. Among the four states directly affected by Katrina, only Mississippi showed continued lower rates of labor force participation and employment and higher rates of unemployment as much as a year later. We also document the higher rates of self-employment among workers in Louisiana and Mississippi up to one year after the storm, compared with pre-disaster levels. At the aggregate level, this pattern suggests an important role for self-employment as part of postdisaster economic recovery, either because of the survival of existing businesses, especially small businesses, or the push or pull toward self-employment on the part of workers who were not previously self-employed.

Such aggregate analyses, common for research on the labor market effects of disasters, mask differential experiences for important subgroups of the population. The supplemental questions added to the CPS following Katrina demonstrate that evacuees were one group that was more severely affected by the hurricane. Although the group of evacuees on average has characteristics associated with lower rates of labor force participation and higher rates of unemployment compared with non-evacuees from the Katrina-affected states, models controlling for observable characteristics show significant labor market effects in the months following the disaster, and even one year later, particularly for evacuees that did not return to their pre-Katrina state. Employment rates of evacuees were below those for non-evacuees and unemployment rates above that of non-evacuees in the months following Katrina and one year later. The differences are most dramatic for non-returnees, who had employment rates one year later that were almost half those of non-evacuees and unemployment rates almost seven times as high. Comparing non-evacuees and returnees from the four Katrinaaffected states, we find that returnees to Louisiana and Mississippi have less favorable outcomes compared with returnees to Florida and Alabama.

Our analysis of individual-level CPS data further suggests that self-employment, whether attributable to push or pull factors, may provide a pathway to employment for prime age individuals affected by the hurricane. Controlling for demographic characteristics, self-employment rates were higher for returning evacuees in all states compared with non-evacuees in those states in the four months immediately following the hurricane but are no different one year later. Non-returnees, again holding observable characteristics constant, have the highest rates of self-employment from March to October 2006, although because of small sample sizes, the differences are only statistically different than non-evacuees at the $10 \%$ level. The reliance on self-employment, especially among nonreturnees, may result from poor job prospects in the wage and salary sector or from new opportunities for starting businesses in the wake of Hurricane Katrina.

The CPS data provide important insights into the labor-market effects of Hurricane Katrina-effects that we can trace for about a year after the disaster-but we must be cautious in the interpretation we attach to the differential labor market outcomes for evacuees compared with non-evacuees and for returnees versus non-returnees. Although we are able to control for a number of observed characteristics in our analysis (and to a greater degree than in many other post-disaster labor market studies), we cannot rule out possible selectivity on the basis of other characteristics that we do not observe. For example, 
controlling for the observed characteristics, those who evacuated or those evacuees who did not return may have been less likely to be working before the hurricane because of other factors or, among those working, they may have been more likely to have been working in self-employment.

Ideally, we would have had information on pre-Katrina labor-market outcomes for our sample to control, at least partially, for these differences. Such information would have also added to our ability to interpret some of our findings, including the greater reliance on self-employment among evacuees, especially non-returnees. Thus, for example, we are unable to discern whether self-employment rates are higher among evacuees because of movements into self-employment or whether evacuees who were previously self-employed are more likely to return to work more rapidly. In addition, the CPS does not provide any data on the characteristics of the respondent's business that would allow us to better integrate findings from research on the effects of disasters on small businesses or businesses in general with what we learn about self-employment at the level of individual workers as part of the road to recovery.

Limitations on the CPS sampling frame also need to be recognized in interpreting our results. In particular, the CPS sample does not include individuals who reside in temporary shelters, hotels, or other nonresidential settings. Given that many Katrina evacuees were located in such settings, particularly immediately after the storm, the CPS data will not fully capture the experiences of the population affected by Katrina, especially in the initial months following the hurricane. To some extent, this issue is addressed by using the CPS sampling weights, which were adjusted to account for the higher noninterview rates in the months immediately following the hurricane. With the passage of time, as more of those affected by the storm relocated to structures that would be included in the CPS sample frame, we would expect our results to be more representative of the experiences of all those affected by Katrina. Nevertheless, the addition of a few questions to an ongoing, large-scale national survey following a high-impact disaster, as was done for the CPS in the aftermath of Hurricane Katrina, has provided important insights into the heterogeneity in labor market experiences for populations affected by the hurricane.

\section{REFERENCES}

Alesch, D.J. 2003. "Complex Urban Systems and Extreme Events: Toward a Theory of Disaster Recovery.” Article, Fairfax, VA: Public Entity Risk Institute.

Alesch, D.J., J.N. Holly, E. Mittler, and R. Nagy. 2001a. "When Small Businesses and Not-forProfit Organizations Collide With Environmental Disasters." Paper presented at The First Annual IIASA-DPRI Meeting Integrated Disaster Risk Management: Reducing Socio-Economic Vulnerability, IIASA, Laxenburg, Austria.

. 2001b. "Organizations at Risk: What Happens When Small Businesses and Not-for-Profits Encounter Natural Disasters.” Technical report. Public Entity Risk Institute, Fairfax, VA.

Blanchflower, D.G. 2000. "Self-employment in OECD Countries." Labour Economics 7:471-506.

Blanchflower, D.G. and A.J. Oswald. 1998. "What Makes an Entrepreneur?” Journal of Labor Economics 7:471-506.

Brown, S.P., S.L. Mason, and R.B. Tiller. 2006. "The Effect of Hurricane Katrina on Employment and Unemployment." Monthly Labor Review 129(8):52-69.

Cahoon, L.S., D.E. Herz, R.C. Ning, A.E. Polivka, M.E. Reed, E.L. Robison, and G.D. Weyland. 2006. "The Current Population Survey Response to Hurricane Katrina." Monthly Labor Review 129(8):40-51.

Clayton, R.L. and J.R. Spletzer. 2006. "Working Mobility Before and After Hurricane Katrina." Monthly Labor Review 129(8):11-21.

Cutter, S.L., C.T. Emrich, J.T. Mitchell, B.J. Boruff, M. Gall, M.C. Schmidtlein, C.G. Burton, and G. Melton. 2006. "The Long Road Home: Race, Class, and Recovery From Hurricane Katrina." Environment 48(2):8-20. 
Dixon, L., J.W. Macdonald, and J. Zissimopoulos. 2007. "Commercial Wind Insurance in the Gulf States: Developments Since Hurricane Katrina and Challenges Moving Forward.” RAND Occasional Paper OP-190-ICJ. RAND Corporation, Santa Monica, CA.

Elliott, J.R. and J. Pais. 2006. "Race, Class, and Hurricane Katrina: Social Differences in Human Response to Disaster." Social Science Research 35:295-321.

Ewing, B.T. and J.B. Kruse. 2005. "Hurricanes and Unemployment.” Working paper, The Center for Natural Hazards Research, East Carolina University.

Ewing, B.T., J.B. Kruse, and M.A. Thompson. 2003a. "A Comparison of Employment Growth and Stability Before and After the Fort Worth Tornado." Environmental Hazards 5:83-91.

. 2003b. "Employment Dynamics and the Nashville Tornado." Journal of Regional Analysis and Policy 34:47-60.

- 2004. "An Empirical Examination of the Corpus Christi Unemployment Rate and Hurricane Bret." Working paper. The Center for Natural Hazards Research, East Carolina University.

- 2009. "Twister! Employment Responses to the 3 May 1999 Oklahoma City Tornado." Applied Economics 41:691-702.

Frankenberg, E., D. McKee, and D. Thomas. 2005. "Health Consequences of Forest Fires in Indonesia." Demography 42:109-29.

Frey, W.H. and A. Singer. 2006. Katrina and Rita Impacts on Gulf Coast Populations: First Census Findings. Washington, DC: Brookings Institution.

Garber, M., L. Unger, J. White, and L. Wohlford. 2006. "Hurricane Katrina's Effects on Industry Employment." Monthly Labor Review 129(8):22-39.

Groen, J.A. and A.E. Polivka. 2008a. "The Effect of Hurricane Katrina on the Labor Market Outcomes of Evacuees." American Economic Review Papers and Proceedings 98(2):43-48.

- 2008b. "Hurricane Katrina Evacuees: Who They Are, Where They Are, and How They Are Faring." Monthly Labor Review 131(3):32-51.

- 2009. "Going Home After Hurricane Katrina: Determinants of Return Migration and Changes in Affected Areas.” BLS Working Paper No. 428. Bureau of Labor Statistics, Washington, DC.

Guimaraes, P., F.L. Hefner, and D.P. Woodward. 1993. "Wealth and Income Effects of Natural Disasters: An Econometric Analysis of Hurricane Hugo." Review of Regional Studies 23:97-114.

Kosanovich, K. 2006. "The Labor Market Impact of Hurricane Katrina: An Overview." Monthly Labor Review 129(8):3-10.

Kroll, C.A., J.D. Landis, Q. Shen, and S. Stryker. 1991. "Economic Impacts of the Loma Prieta Earthquake: A Focus on Small Business." Studies on the Loma Prieta Earthquake No. 3. The University of California Transportation Center, University of California, Berkeley.

Manser, M.E. and G. Picot. 1999. "The Role of Self-employment in U.S. and Canadian Job Growth." Monthly Labor Review 122(4):10-25.

Moore, C.S. and R.E. Mueller. 2002. 'The Transition From Paid to Self-employment in Canada: The Importance of Push Factors." Applied Economics 34:791-801.

Pielke, R.A. Jr., J. Gratz, C.W. Landsea, D. Collins, M.A. Saunders, and R. Musulin. 2008. "Normalized Hurricane Damages in the United States: 1900-2005." Natural Hazards Review 9(1):29-42.

Rodgers, J.L., C.A. St. John, and R. Coleman. 2005. "Did Fertility Go up After the Oklahoma City Bombing? An Analysis of Births in Metropolitan Counties in Oklahoma, 1990-1999." Demography 42:675-92.

Rodriguez, H., E.L. Quarantelli, and R. Dynes, eds. 2006. Handbook of Disaster Research. New York: Springer.

Sastry, N. 2002. "Forest Fires, Air Pollution, and Mortality in Southeast Asia." Demography 39: $1-23$.

- 2009. "Tracing the Effects of Hurricane Katrina on the Population of New Orleans: The Displaced New Orleans Residents Pilot Study.” Sociological Methods and Research 38:171-96.

Schuetze, H.J. 2000. "Taxes, Economic Conditions and Recent Trends in Self-employment: A Canada-U.S. Comparison.” Labour Economics 7:507-44. 
Schuster, M.A., B.D. Stein, L.H. Jaycox, R.L. Collins, G.N. Marshall, M.N. Elliott, A.J. Zhou, D.E. Kanouse, J.L. Morrison, and S.H. Berry. 2001. "A National Survey of Stress Reactions After the September 11, 2001, Terrorist Attacks." New England Journal of Medicine 345:1507-12.

Simpson, W. and R. Sproule. 1998. "Econometric Analysis of Canadian Self-employment Using SLID.” Income and Labour Dynamics Working Paper No. 98-16. Statistics Canada, November.

Skidmore, M. and H. Toya. 2002. "Do Natural Disasters Promote Long Run Growth?" Economic Inquiry 40:664-87.

Smith, S.K. and C. McCarty. 1996. "Demographic Effects of Natural Disasters: A Case Study of Hurricane Andrew." Demography 33:265-75.

Tierney, K.J. 2003. "Conceptualizing and Measuring Organizational and Community Resilience: Lessons From the Emergency Response Following the September 11, 2001 Attack on the World Trade Center." Preliminary Paper No. 329. University of Delaware Disaster Research Center, Newark, DE.

Tierney, K.J. and M. Bruneau. 2007. "Conceptualizing and Measuring Resilience: A Key to Disaster Loss Reduction.” TR News 250(May-June):14-17.

U.S. Department of Commerce, NOAA Satellite and Information Service. 2006. "Climate of 2005 Atlantic Hurricane Season.” Available online at http://www.ncdc.noaa.gov/oa/climate/ research/2005/hurricanes05.html.

Vigdor, J.L. 2007. "The Katrina Effect: Was There a Bright Side to the Evacuation of Greater New Orleans?" The B.E. Journal of Economic Analysis and Policy (Advances) 7(1): Article 64. Available online at: http://www.bepress.com/bejeap/vol7/iss1/art64.

Webb, G.R., K.J. Tierney, and J.M. Dahlhamer. 2000. "Business and Disasters: Empirical Patterns and Unanswered Questions." Natural Hazards Review 1(2):83-90.

—. 2002. "Predicting Long-term Business Recovery From Disaster: A Comparison of the Loma Prieta Earthquake and Hurricane Andrew." Environmental Hazards 4:45-58.

Wright, J.D. and P.H. Rossi, eds. 1981. Social Science and Natural Hazards. Cambridge, MA: Abt Books. 